\title{
Cold Compress
}

National Cancer Institute

\section{Source}

National Cancer Institute. Cold Compress. NCI Thesaurus. Code C153474.

A chilled cloth or similar dressing applied to the skin. 